\title{
Effects of standard and total two-field lymph node dissection on prognosis of patients undergoing Esophagectomy
}

\author{
Qiang Guo ${ }^{1}$, Hefei $\mathrm{Li}^{2}$, \\ Haibo Wang ${ }^{3}$, Duo Zhang ${ }^{4}$, Yonghui $L^{5}$
}

\begin{abstract}
Objectives: To investigate the effects of standard two-field lymph node dissection (2FLND) and total 2FLND on the short-term and long-term clinical efficacy and complications of patients undergoing esophagectomy. Methods: The clinical data of 268 patients undergoing radical Ivor-Lewis esophagectomy in our hospital from January 2008 to November 2015 were analyzed retrospectively. According to different methods of lymph node dissection (LND), the patients were divided into standard 2FLND group $(n=121)$ and total 2FLND group $(n=147)$. The LND status, postoperative complications, survival rate and lymph node recurrence of the two groups were analyzed.

Results: Lymph node metastasis rate showed no statistically significant difference between the standard 2FLND group and the total 2FLND group $(71.1 \%$ and $63.3 \%$, respectively, $P>0.05)$. The incidence of postoperative complications was 5.8\% (7/121) in the standard 2FLND group, which was lower than that in the total 2FLND group [17.0\% $(25 / 147)]$, with a statistically significant difference $\left(x^{2}=7.948, P<0.01\right)$. The 5-year survival rate of the standard 2FLND group and the total 2FLND group was $29.8 \%$ and $28.6 \%$, respectively, without statistically significant difference $\left(x^{2}=0.005, P>0.05\right)$. The lymph node recurrence rate in the standard 2 FLND group was $41.3 \%(50 / 121)$, which was higher than $19.0 \%(28 / 147)$ of the total 2FLND group $\left(x^{2}=15.959, P<0.01\right)$.

Conclusion: Compared with standard 2FLND, total 2FLND does not improve the postoperative survival of patients with esophageal carcinoma, and the risk of complications is higher.
\end{abstract}

KEYWORDS: Esophageal carcinoma, Esophagectomy, Lymph node dissection, Survival rate.

doi: https://doi.org/10.12669/pjms.38.4.4031

How to cite this:

Guo $Q$, Li H, Wang H, Zhang D, Li Y. Effects of standard and total two-field lymph node dissection on prognosis of patients undergoing Esophagectomy. Pak J Med Sci. 2022;38(4):950-954. doi: https://doi.org/10.12669/pjms.38.4.4031

This is an Open Access article distributed under the terms of the Creative Commons Attribution License (http://creativecommons.org/licenses/by/3.0), which permits unrestricted use, distribution, and reproduction in any medium, provided the original work is properly cited.

Qiang Guo,

Hefei Li,

Haibo Wang,

Duo Zhang,

Yonghui Li,

1-5: Department of Thoracic Surgery,

Affiliated Hospital of Hebei University,

Baoding, Hebei 071000,

P.R. China.

Correspondence:

Yonghui Li,

Department of Thoracic Surgery, Affiliated Hospital of Hebei University, Baoding, Hebei 071000, P.R. China.

Email: yunkouhuanlaifa@163.com

* Received for Publication:

* $1^{\text {st }}$ Revision Received:

* $2^{\text {nd }}$ Revision Received:

* Revision Accepted: *

\section{INTRODUCTION}

Radical esophagectomy is the preferred treatment method for esophageal carcinoma (EC) 1 , and lymphatic metastasis is the main cause for the failure of radical esophagectomy. ${ }^{2}$ Studies have shown that the lymph node metastasis rate of esophageal cancer is as high as $26.2 \%-37.8 \%$, and the deeper the tumor infiltration, the easier the lymph node metastasis. ${ }^{3}$ However, there is no uniform standard for lymph node dissection (LND) in esophagectomy up to now. Traditional twofield lymph node dissection (2FLND) is commonly used in China. Some researchers ${ }^{4}$ advocate the use of extended 2FLND, but its efficacy is still uncertain. In this study, the clinical data of patients undergoing radical esophagectomy in 
our hospital from January 2008 to November 2015 were reviewed, and the effects of different LND methods on the clinical efficacy and complications of patients with EC were explored, so as to guide the clinical selection of the optimal LND method.

\section{METHODS}

The clinical data of 268 patients undergoing radical esophagectomy and regular follow-up in our hospital from January 2008 to December 2015 were retrospectively analyzed. All the patients received Ivor-Lewis esophagectomy, including 121 patients undergoing standard 2FLND (standard 2FLND group) and 147 patients receiving total 2FLND (total 2FLND group). All the patients were confirmed as esophageal squamous cell carcinoma (ESCC) by preoperative gastroscope-guided pathological examination. Electrocardiography (ECG), esophagography, and neck, chest and upper abdomen CT examinations were performed routinely. Patients with cervical lymph node metastasis and preoperative neoadjuvant therapy were excluded. No statistically significant differences were found in clinical data including gender, age and lesion site between the standard 2FLND group and the total 2FLND group $(P>$ $0.05)$, as shown in Table-I.

Ethical Approval: The study was approved by the Institutional Ethics Committee of Affiliated Hospital of Hebei University on March 1, 2016, and written informed consent was obtained from all participants.

Methods: All the patients received Ivor-Lewis esophagectomy and LND. The lymph nodes were grouped according to the AJCC lymph node distribution pattern. The scope of dissection in the standard 2FLND group included: lymph node group 16 under the diaphragm in the upper abdomen, lymph node groups 17, 18, 19 and 20 at the upper edge of pancreas, and lymph node groups 7, 8, 9 and 15 in the chest. On the basis of the standard 2FLND group, lymph node groups 2 and 4 were additionally dissected in the total 2FLND group. All patients were given individualized chemotherapy after surgery. All the patients were followed up by telephone of our department till the end of October 2020, with follow-up duration of 4-86 months (median, 35 months). LND status, postoperative complications, survival rate and lymph node recurrence were statistically compared between the two groups.

Statistical Analyses: SPSS19.0 was used for statistical analysis. Survival analysis was carried
Table-I: Comparison in clinical data between standard 2FLND group and total 2FLND group.

\begin{tabular}{|c|c|c|c|c|}
\hline Item & $\begin{array}{l}\text { Standard } \\
2 F L N D \\
\text { group } \\
(n=121)\end{array}$ & $\begin{array}{c}\text { Total } \\
2 \text { FLND } \\
\text { group } \\
(n=147)\end{array}$ & $x^{2} / t$ & $P$ \\
\hline Gender & & & 1.327 & $>0.05$ \\
\hline Male & 116 & 136 & & \\
\hline Female & 5 & 11 & & \\
\hline Age (year) & $58.1 \pm 10.2$ & $58.6 \pm 9.7$ & 0.410 & $>0.05$ \\
\hline Complications & & & 0.059 & $>0.05$ \\
\hline Yes & 94 & 116 & & \\
\hline No & 27 & 31 & & \\
\hline Lesion site & & & 0.259 & $>0.05$ \\
\hline $\begin{array}{l}\text { Upper seg- } \\
\text { ment }\end{array}$ & 11 & 16 & & \\
\hline $\begin{array}{l}\text { Middle seg- } \\
\text { ment }\end{array}$ & 89 & 107 & & \\
\hline $\begin{array}{l}\text { Lower seg- } \\
\text { ment }\end{array}$ & 21 & 24 & & \\
\hline Gross type & & & 0.675 & $>0.05$ \\
\hline $\begin{array}{l}\text { Superficial } \\
\text { type }\end{array}$ & 5 & 9 & & \\
\hline $\begin{array}{l}\text { Medullary } \\
\text { type }\end{array}$ & 83 & 102 & & \\
\hline $\begin{array}{l}\text { Ulcerative } \\
\text { type }\end{array}$ & 20 & 23 & & \\
\hline $\begin{array}{l}\text { Fungoid } \\
\text { type }\end{array}$ & 11 & 10 & & \\
\hline $\begin{array}{l}\text { Constrictive } \\
\text { type }\end{array}$ & 2 & 3 & & \\
\hline TNM stage & & & 0.405 & $>0.05$ \\
\hline Ia & 5 & 6 & & \\
\hline $\mathrm{Ib}$ & 7 & 9 & & \\
\hline IIa & 16 & 19 & & \\
\hline $\mathrm{IIb}$ & 55 & 63 & & \\
\hline IIIa & 23 & 31 & & \\
\hline $\mathrm{IIIb}$ & 15 & 19 & & \\
\hline $\begin{array}{l}\text { Tumor } \\
\text { diameter } \\
(\mathrm{cm})\end{array}$ & $5.3 \pm 1.8$ & $5.1 \pm 1.9$ & 0.878 & $>0.05$ \\
\hline $\begin{array}{l}\text { Vascular } \\
\text { tumor } \\
\text { thrombus }\end{array}$ & & & 0.030 & $>0.05$ \\
\hline Yes & 18 & 23 & & \\
\hline No & 103 & 124 & & \\
\hline
\end{tabular}


Prognosis of Patients Undergoing Esophagectomy

Table-II: Comparison in LND status between two groups (\%).

\begin{tabular}{|c|c|c|c|c|}
\hline Item & $\begin{array}{c}\text { Standard } 2 \text { FLND } \\
\text { group }(n=121)\end{array}$ & $\begin{array}{c}\text { Total } 2 \text { FLND } \\
\text { group }(n=147)\end{array}$ & $x^{2} / t$ & $P$ \\
\hline Lymph node metastasis rate & $71.1(86 / 121)$ & $63.3(93 / 147)$ & 1.825 & $>0.05$ \\
\hline Lymph node metastasis rate in the upper abdomen & $57.9(70 / 121)$ & $54.4(80 / 147)$ & 0.317 & $>0.05$ \\
\hline Lymph node metastasis rate in the mid-inferior mediastinum & $39.7(48 / 121)$ & $34.0(50 / 147)$ & 0.915 & $>0.05$ \\
\hline Lymph node metastasis rate in the superior mediastinum & $13.2(16 / 121)$ & $20.4(30 / 147)$ & 2.409 & $>0.05$ \\
\hline
\end{tabular}

out using the Kaplan-Meier method and Log-Rank test. The measurement data were expressed as mean \pm standard deviation $(\bar{x} \pm s)$, and compared by the $t$ test. The enumeration data were compared using the $\chi^{2}$ test. $P<0.05$ was considered as statistically significant.

\section{RESULTS}

A total of 3,675 lymph nodes were dissected in 121 patients of the standard 2FLND group. Among them, 86 patients showed lymph node metastasis by postoperative pathology, with 366 metastatic lymph nodes (lymph node metastasis rate, $71.1 \%$ ). In the total 2 FLND group, a total of 4,516 lymph nodes were dissected from the 147 patients, 93 of which presented lymph node metastasis by postoperative pathology (501 metastatic lymph nodes; lymph node metastasis rate, $63.3 \%)$. The lymph node metastasis rate showed no statistically significant difference between the two groups $(P>0.05)$. No statistically significant differences were found in lymph node metastasis rate in the upper abdomen, midinferior mediastinum or superior mediastinum between the two groups $(P>0.05)$, as seen in Table-II.

The incidence of postoperative complications in the total 2FLND group was $17.0 \%$ (25/147), which was significantly higher than 5.8\% (7/121) in the standard 2FLND group $\left(\chi^{2}=7.948, P<0.01\right)$. The proportions of patients with postoperative recurrent laryngeal nerve injury and respiratory failure in the total 2FLND group were significantly higher than those in the standard 2FLND group $(P<0.01, P<0.05$, Table-III).

The 5-year survival rate of the standard 2FLND group was $29.8 \%$, with the median survival time of 41 months $(95 \% \mathrm{CI}=37.5-45.8)$. In the total 2FLND group, the 5-year survival rate was $28.6 \%$, with the median survival time of 42 months $(95 \% \mathrm{CI}=37.1-46.7)$. The survival showed no statistically significant difference between the two groups $\left(\chi^{2}=0.005, P>0.05\right)$. The lymph node recurrence rate in the standard 2FLND group was $41.3 \%$ (50/121), which was much higher than $19.0 \%(28 / 147)$ of the total 2FLND group $\left(\chi^{2}=\right.$ $15.959, P<0.01)$.

\section{DISCUSSION}

The surgical treatment for EC aims to prolong the survival time and improve the quality of life of the patients. ${ }^{5}$ LND is directly related to the postoperative survival rate of the patients. ${ }^{6}$ Especially in the patients with lower thoracic EC, lymph node metastasis rate is very high, reaching about $40 \% .^{7}$ Therefore, the lymph nodes in the lesion area should be thoroughly dissected as far as possible during esophagectomy, in addition to resecting the cancerous esophagus with sufficient length. ${ }^{8-10}$ Standard 2FLND, including midinferior mediastinal and abdominal lymph nodes, is commonly used by many domestic scholars.

Table-III: Comparison in postoperative complications between two groups [n (\%)].

\begin{tabular}{|c|c|c|c|c|}
\hline Item & $\begin{array}{c}\text { Standard } 2 \text { FLND } \\
\text { group }(n=121)\end{array}$ & $\begin{array}{c}\text { Total } 2 \text { FLND } \\
\text { group }(n=147)\end{array}$ & $x^{2} / t$ & $P$ \\
\hline Recurrent laryngeal nerve injury & $2(1.7)$ & $25(17.0)$ & 17.270 & $<0.01$ \\
\hline Anastomotic leakage & $3(2.5)$ & $2(1.4)$ & 0.454 & $>0.05$ \\
\hline Chylothorax & $1(0.8)$ & $2(1.4)$ & 0.170 & $>0.05$ \\
\hline Respiratory failure & $1(0.8)$ & $9(6.1)$ & 5.182 & $<0.05$ \\
\hline
\end{tabular}


However, superior mediastinal and pararecurrent laryngeal nerve lymph nodes, which are prone to metastasis in EC, can not be completely dissected, resulting in that the postoperative 5 -year survival rate of EC patients in China is only $30 \%-35 \% .{ }^{11}$ With the understanding of the rule of lymph node metastasis in EC, total 2FLND has been advocated. On the basis of standard 2FLND, superior mediastinal lymph nodes in bilateral recurrent laryngeal nerve are also included in total 2FLND. Some scholars believe that ${ }^{12,13}$ total LND expands the scope of dissection, increases the number of dissected lymph nodes, improves the accuracy of postoperative pathological staging and reduces the probability of local recurrence. In our study, the lymph node metastasis rate of the standard 2FLND group was $71.1 \%$, which was higher than $63.3 \%$ of the total 2FLND group, but the difference was not statistically significant $(P>$ $0.05)$. There were also no statistically significant differences in lymph node metastasis rate of the upper abdomen, mid-inferior mediastinum or superior mediastinum between the two groups $(P>0.05)$. These results suggest no significant difference in lymph node metastasis rate in EC between standard and total 2FLND. This may be related to the characteristics of lymph node metastasis in EC. Because the lymphatic network between the esophagus and the mediastinum connects each other, lymph node metastasis can be not only continuous, but also bidirectional and skipped. ${ }^{14,15}$ However, Liu Liang et al. ${ }^{16}$ have confirmed that total 2FLND can reduce the rate of lymph node metastasis. We believe that although total 2FLND increased the scope and number of dissected lymph nodes, the results of this study were affected in that lymph node metastasis of EC always occurs early, and most patients in this study were locally advanced. However, in terms of long-term efficacy, the postoperative lymph node recurrence rate in the standard 2FLND group was $41.3 \%$ (50/121), which was much higher than $19.0 \%(28 / 147)$ of the total 2FLND group. Therefore, the scope of lymph node dissection has a great impact on lymph node recurrence. The scope of standard 2FLND is small, which increases the probability of lymph node recurrence. Wu Changrong et al. ${ }^{17}$ have confirmed that expanding the scope of LND in EC can improve the postoperative 5-year survival rate of the patients. However, our results showed that the 5-year survival rate was $29.8 \%$ in the standard 2FLND group and $28.6 \%$ in the total 2FLND group. There was no statistically significant difference in the 5-year survival rate between the two groups, indicating that the two LND methods have no obvious effect on the 5-year survival rate of EC patients. Zhang Aimin et al. ${ }^{18}$ proposed that metastatic lymph nodes are an important factor affecting the prognosis of EC. In patients with multi-group and multi-field lymph node metastasis, the tumors have become systemic lesions from local lesions, and surgical resection is still difficult to achieve the desired effect. In this study, although the total 2FLND group presented a lower recurrence rate, there was no difference in the lymph node metastasis rate from the standard 2FLND group, so there was no improvement in the long-term survival rate. It has been reported that ${ }^{19}$ the 5 -year survival rate of EC patients with lymph node metastasis after surgical resection is only $12.6 \%-19.7 \%$, which is much lower than that in our study.

The enlarged scope of LND increased the incidence of surgical complications. Zhang Kun et $a .^{20}$ have confirmed that total 2FLND is likely to cause recurrent laryngeal nerve injury, with an incidence rate of $0.4 \%-65.0 \%$. In our study, the incidence of postoperative complications in the total 2FLND group was $17.0 \%$, which was significantly higher than that in the standard 2FLND group (5.8\%). Moreover, the proportions of patients with recurrent laryngeal nerve injury and respiratory failure in the total 2FLND group were significantly higher than those in the standard 2FLND group. Therefore, the incidence of postoperative complications after total 2FLND is high. This study compares and evaluates the efficacy of standard twofield lymph node dissection and total two-field lymph node dissection in patients undergoing esophageal cancer surgery from the perspectives of postoperative survival rate and complication rate. It provides clinical guidance for the choice of lymph node dissection during esophageal cancer surgery.

Limitations of this study It includes small sample size and retrospective nature of the study. The advantages and disadvantages of these two lymph node dissections should also be evaluated more comprehensively from other aspects besides postoperative survival rate and complication rate. 


\section{CONCLUSION}

Total 2FLND did not improve the postoperative survival of patients with EC, on the contrary, it brought a higher risk of complications. Therefore, patients with EC should be accurately evaluated before surgery, so as to adopt appropriate dissection methods.

\section{Declaration of conflicting interest: None.}

Funding None.

\section{REFERENCES}

1. Liu F, Wang W, Wang C, Peng X. Enhanced recovery after surgery (ERAS) programs for esophagectomy protocol for a systematic review and meta-analysis. Medicine (Baltimore). 2018;97(8):e0016. doi: 10.1097/ MD.0000000000010016

2. Liu S, Bai Y, Zhao B, Ren H, Qin X, Qi B. Analysis of prognostic factors in patients with recurrent and metastatic esophageal carcinoma. Zhonghua Zhong Liu Za Zhi. 2015;37(2):143-147.

3. Zhang M, Zang R, Lei W, Xue Q, Gao S. Pattern of lymphatic metastasis and risk factor of esophageal carcinoma that invades less than adventitia. Zhonghua Wei Chang Wai Ke Za Zhi. 2015;18(9):893-896.

4. Xue HC, Wu CR, Zhang ZB, Zhu ZH, Ma ZK, Gao J. Regulations and lymphadenectomy strategy of mediastinal and upper abdominal lymph node metastasis in thoracic esophageal carcinoma. Ai Zheng. 2007;26(9):1020-1024.

5. Borggreve A, Kingma B, Domrachev S, Koshkin M, Ruurda J, Hillegersberg R, et al. Surgical treatment of esophageal cancer in the era of multimodality management. Ann N Y Acad Sci. 2018;1434(1):192-209. doi: 10.1111/nyas.13677

6. Yuan L, Mao Y. [Thoracic recurrent laryngeal nerve lymph node metastasis guides the cervical lymph node dissection of patients with esophageal cancer]. Zhonghua Zhong Liu Za Zhi. 2019;41(1):10-14. doi: 10.3760/cma.j.is sn.0253-3766.2019.01.003

7. Lu ZM, Zhang H, Wang MH, Cui DH, Yang YQ, Huang HZ. Lymphatic metastasis intensity of and lymphadenectomy for thoracic esophageal squamous cell carcinoma. Ai Zheng. 2006;25(5):604-608.

8. Shang Q, Wang Y, Yang Y, Hu W, Chen L. Pattern of subcarinal lymph node metastasis and dissection strategy for thoracic esophageal cancer. J Thorac Dis. 2020;12(10):56675677. doi: $10.21037 /$ jtd-20-1776

9. Wang Z, Mao Y, Gao S, Li Y, Tan L, Daiko H, et al. Lymph node dissection and recurrent laryngeal nerve protection in minimally invasive esophagectomy. Ann N Y Acad Sci. 2020;1481(1):20-29. doi: 10.1111/nyas.14427

10. Soeno T, Harada H, Hosoda K, Mieno H, Ema A, Ushiku $\mathrm{H}$, et al. Lymph Node Progression and Optimized Node Dissection of Middle Thoracic Esophageal Squamous Cell Carcinoma in the Latest Therapeutic Surgical Strategy. Ann Surg Oncol. 2019;26(4):996-1004. doi: 10.1245/s10434019-07190-5
11. de Vos-Geelen J, Geurts SM, van Putten M, Valkenburgvan Iersel LB, Grabsch HI, Haj Mohammad N, et al. Trends in treatment and overall survival among patients with proximal esophageal cancer. World J Gastroenterol. 2019;25(47):6835-6846. doi: 10.3748/wjg.v25.i47.6835

12. Kun Z, Qirong X, Wenping W. Relationship between number of dissected lymph nodes and postoperative complications in esophageal carcinoma. Chinese J Gastrointestinal Surg. 2012;15(4):342-345.

13. Lin C, Cheng C, Liu C, Lee M, Hsiao M, Shih C, et al. Radical Lymph Node Dissection in Primary Esophagectomy for Esophageal Squamous Cell Carcinoma. Ann Thorac Surg. 2015;100(1):278-286. doi: 10.1016/j.athoracsur.2015.02.053

14. Wang Y, Zhu L, Xia W, Wang F. Anatomy of lymphatic drainage of the esophagus and lymph node metastasis of thoracic esophageal cancer. Cancer Manag Res. 2018;10:6295-6303. doi: 10.2147/CMAR.S182436

15. Jepsen D, Fiehn A, Svendsen B, Achiam M, Federspiel B. Isolated tumor cells in the regional lymph nodes in patients with squamous cell carcinoma of the esophagus are rarely observed but often represent part of a true metastasis. Ann Diagn Pathol. 2020;45:151478. doi: 10.1016/j. anndiagpath.2020.151478

16. Liang L, Ming G, Lixin Y. Feasibility and safety analysis of complete thoracoscopic combined with laparoscopic esophagectomy and thoracic and abdominal lymph node dissection for esophageal cancer. Med Inform. 2014;(37):62-62.

17. Wu CR, Xue HC, Zhu ZH, Zhang ZB, Geng CY, Ma ZK, et al. Analysis of the therapeutic effect of esophagectomy with extended 2-field lymph node dissection for esophageal carcinoma. Zhonghua Zhong Liu Za Zhi. 2009;31(8):630633.

18. Aimin Z, Qingbo Z. Multivariate analysis of lymph node metastasis in patients with esophageal cancer. J Chin Physician. 2014;16(9):1240-1242

19. Hsu PK, Huang CS, Hsieh CC, Wu YC, Hsu WH. Role of right upper mediastinal lymph node metastasis in patients with esophageal squamous cell carcinoma after tri-incisional esophagectomies. Surgery. 2014;156(5):1269-1277. doi: 10.1016/j.surg.2014.05.007

20. Kun Z, Qirong X, Wenping W. Relationship between number of dissected lymph nodes and postoperative complications in esophageal carcinoma. Chin J Gastrointest Surg. 2012;15(4):342-345.

\section{Authors' Contributions:}

QG \& YL: Designed this study and prepared this manuscript, and are responsible and accountable for the accuracy or integrity of the work.

HL \& HW: Collected and analyzed clinical data.

DZ: Significantly revised this manuscript. 